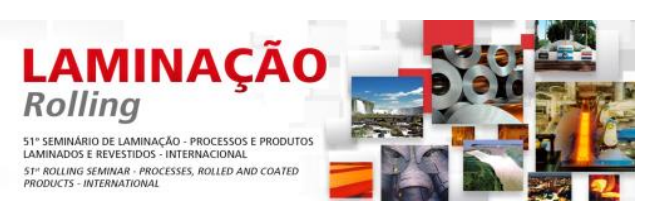

\title{
NEW SERVICES TO PRODUCE HIGH QUALITY COATED STRIP*
}

\begin{abstract}
In order to increase the production of Advanced High Strength Steel (AHSS) as well as to fulfill the growing expectations of various industries served, steelmakers must have wide- ranging know-how in terms of plant technology, operation, processes, quality control and, last but not least, know-how for AHSS including certification procedures. MET/Con is highly focused on the production of coated AHSS with tensile strengths higher than $600 \mathrm{MPa}$. Common heating and cooling technologies are unable to handle high alloyed steel grades - pre-oxidation and rapid cooling technologies have been developed to face these new challenges. MET/CON and Drever International have the knowledge to produce newest steel grades with these technologies.
\end{abstract}

Keywords: AHSS; UHSS; Pre-oxidation; Internal and external oxidation; Rapid cooling.

* Technical contribution to the 51st Rolling Seminar - Processes, Rolled and Coated Products, October $28^{\text {th }}$ to $31^{\text {st }}, 2014$, Foz do Iguaçu, PR, Brazil. 


\section{INTRODUCTION}

Today, lightweight design is one of the biggest challenges for the automobile industry, supplier and development aided services [1]. In the highly competitive automotive industry cost is also extremely important with regard to material selection. Due to its comparable low production costs, steel is still the most important material for automotive engineering. Current vehicles are made at the average $70 \%$ out of steel due to its advantageous technological properties and its outstanding profitability as well as resource-efficiency and environmental compatibility. Advanced High Strength Steels (AHSS) and Ultra High Strength Steels (UHSS) with tensile strengths above $800 \mathrm{MPa}$ are the material of choice for lightweight design. Use of these materials enable the automobile industry to maintain design freedom, crash safety along with weight reduction in the automobile frame.

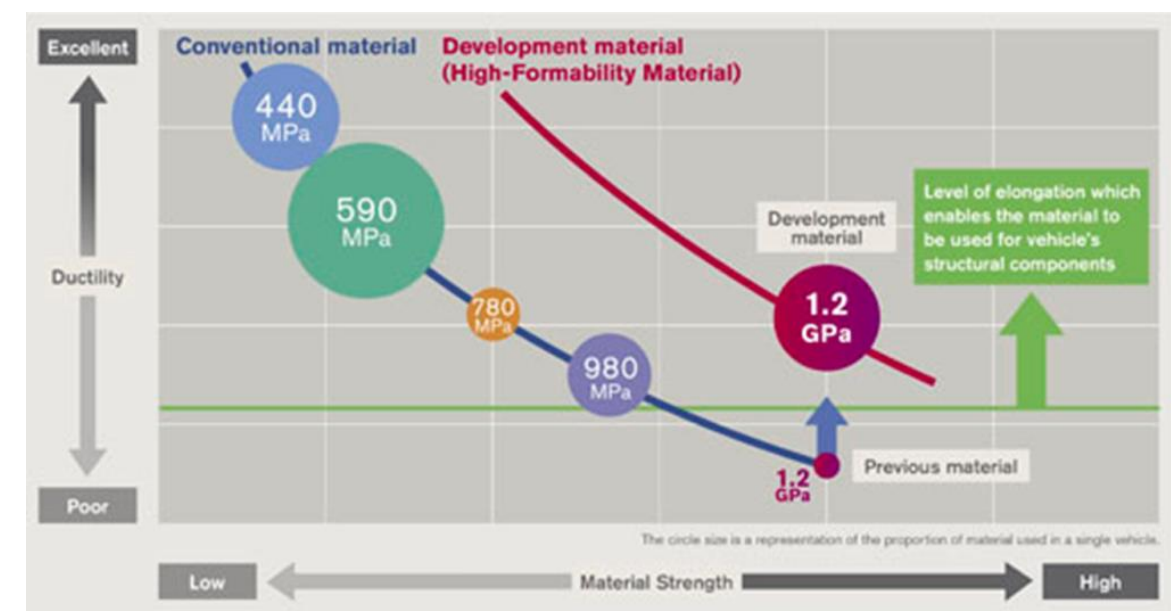

Figure 1: Properties of available steel grades

Source: http://www.nissan-global.com/EN/NEWS/2013/_STORY/130312-01-e.html

According to the Corporate Average Fuel Economy (CAFE) program, automobile manufactures have to meet the standards for the sales-weighted average fuel economy of their passenger vehicle fleets. The most recently published standards cover model years 2017 through 2021. Fuel consumption is another common regulatory metric that is the reciprocal of fuel economy. Rates of reduction for fuel consumption standards are proportional to reduction rates for Green House Gas (GHG) or Carbon dioxide- $\left(\mathrm{CO}_{2}\right)$ emissions, expressed as grams of pollutant per distance traveled [2]. * Technical contribution to the $51^{\text {st }}$ Rolling Seminar - Processes, Rolled and Coated Products,
October $28^{\text {th }}$ to $31^{\text {st }}$, 2014, Foz do lguaçu, PR, Brazil. 

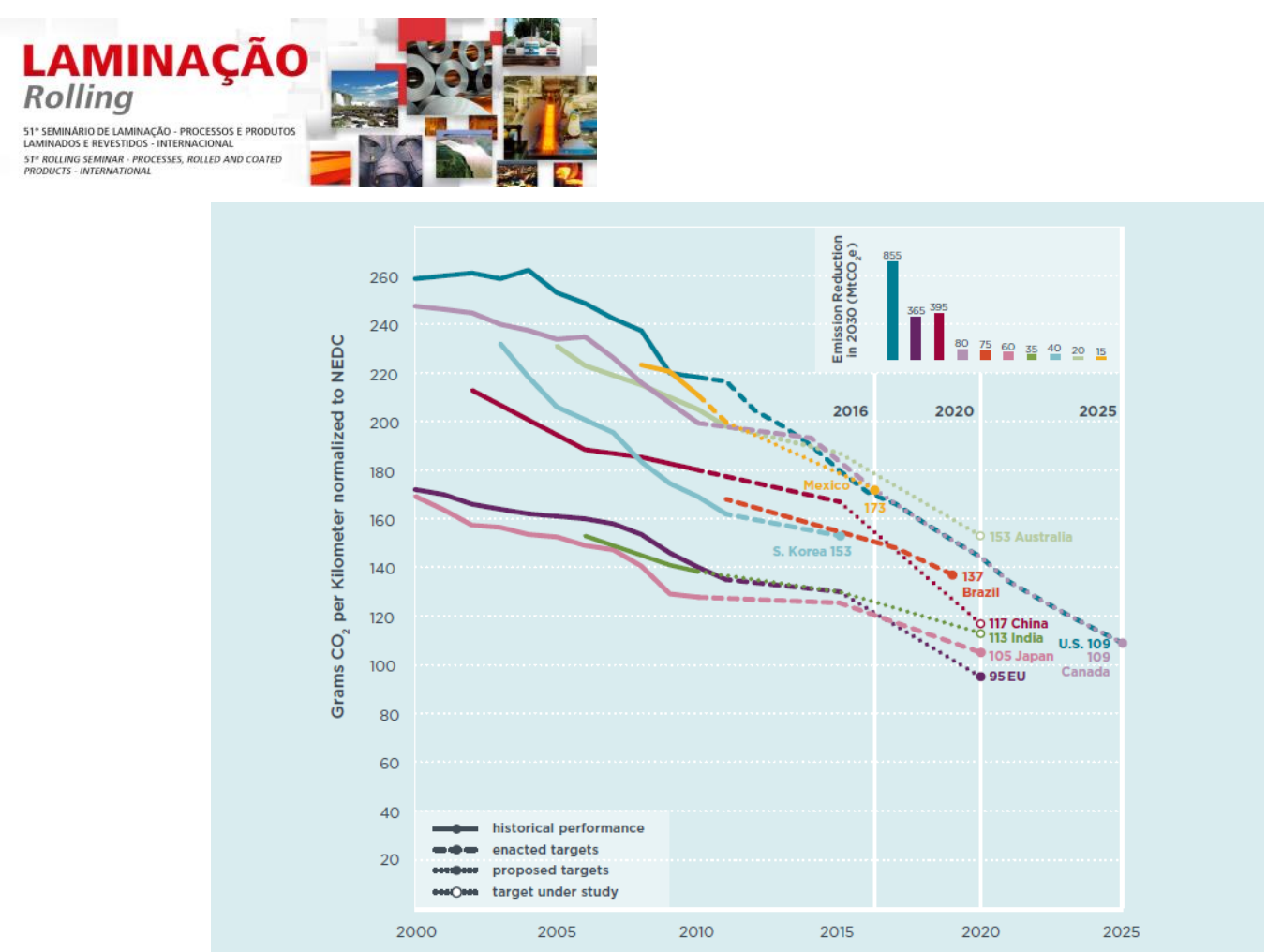

Figure 2: Decrease $\mathrm{CO}_{2}$ emissions of vehicles: Global $\mathrm{CO}_{2}$ regulation trends Source: ICCT Roadmap Energy Report, Nov. 2012

The 2021 CAFE-standards are 38 to 51 miles per gallon $(\mathrm{mpg})$ for cars and 25 to 42 $\mathrm{mpg}$ for light trucks [3]. The European standard for 2021 is $95 \mathrm{gram} \mathrm{CO}_{2} / \mathrm{km}$. To compare US-standard with European standard, 51 miles per gallon is equal to 108 gram $\mathrm{CO}_{2} / \mathrm{km}$. $95 \mathrm{gram} \mathrm{CO} / \mathrm{km}$ is equal to 62 miles per gallon.

Table 1: Estimated average required Fleet-wide Fuel Economy $(\mathrm{mpg})$ under Footprint-based CAFE Standard

\begin{tabular}{|l|l|l|l|l|l|l|l|l|l|l|}
\hline & $\begin{array}{l}\text { MY } \\
\text { Baseline }\end{array}$ & $\mathbf{2 0 1 7}$ & $\mathbf{2 0 1 8}$ & $\mathbf{2 0 1 9}$ & $\mathbf{2 0 2 0}$ & $\mathbf{2 0 2 1}$ & $\mathbf{2 0 2 2}$ & $\mathbf{2 0 2 3}$ & $\mathbf{2 0 2 4}$ & $\mathbf{2 0 2 5}$ \\
\hline Passenger & 2008 & $40.1-$ & $41.6-$ & $43.1-$ & $44.8-$ & $46.8-$ & $49.0-$ & $51.2-$ & $53.6-$ & $56.2-$ \\
cars & 2010 & 39.6 & 41.1 & 42.5 & 44.2 & 46.1 & 48.2 & 50.5 & 52.9 & 55.3 \\
\hline \multirow{2}{*}{ Light trucks } & 2008 & $29.4-$ & $30.0-$ & $30.6-$ & $31.2-$ & $33.3-$ & $34.9-$ & $36.6-$ & $38.5-$ & $40.3-$ \\
& 2010 & 29.1 & 29.6 & 30.0 & 30.6 & 32.6 & 34.2 & 35.8 & 37.5 & 39.3 \\
\hline \multirow{2}{*}{ Combined } & 2008 & $35.4-$ & $36.5-$ & $37.7-$ & $38.9-$ & $41.0-$ & $43.0-$ & $45.1-$ & $47.4-$ & $49.7-$ \\
& 2010 & 35.1 & 36.1 & 37.1 & 38.3 & 40.3 & 42.3 & 44.3 & 46.5 & 48.7 \\
\hline
\end{tabular}

Source: Federal Register / Vol. 77, No. 199 / Monday, October 15, 2012 / Rules and Regulations

Safety regulations have accelerated the use of advanced high strength steels in vehicles. The National Highway Traffic Safety Administration (NHTSA) sets standards for vehicle safety, such as those for impact resistance, vehicle occupant restraints and fuel economy [4]. Meeting these safety standards often requires addition of weight to the vehicle. While adding safety components the auto industry is still looking to dramatically reduce the weight of vehicles. One kilogram weight reduction saves approximately $20 \mathrm{~kg} \mathrm{CO}$. FORD has stated in 2012 a goal of cutting $340 \mathrm{~kg}$ from its vehicles by 2020. Renault and PSA Peugeot Citroen have estimated a goal of cutting $200 \mathrm{~kg}$ by 2018, while Hyundai planned in 2010 to cut its average vehicle weight by $10 \%(150 \mathrm{~kg})$ over five years. 


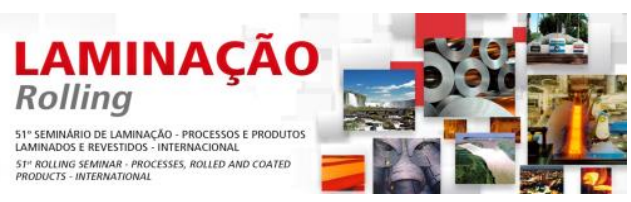
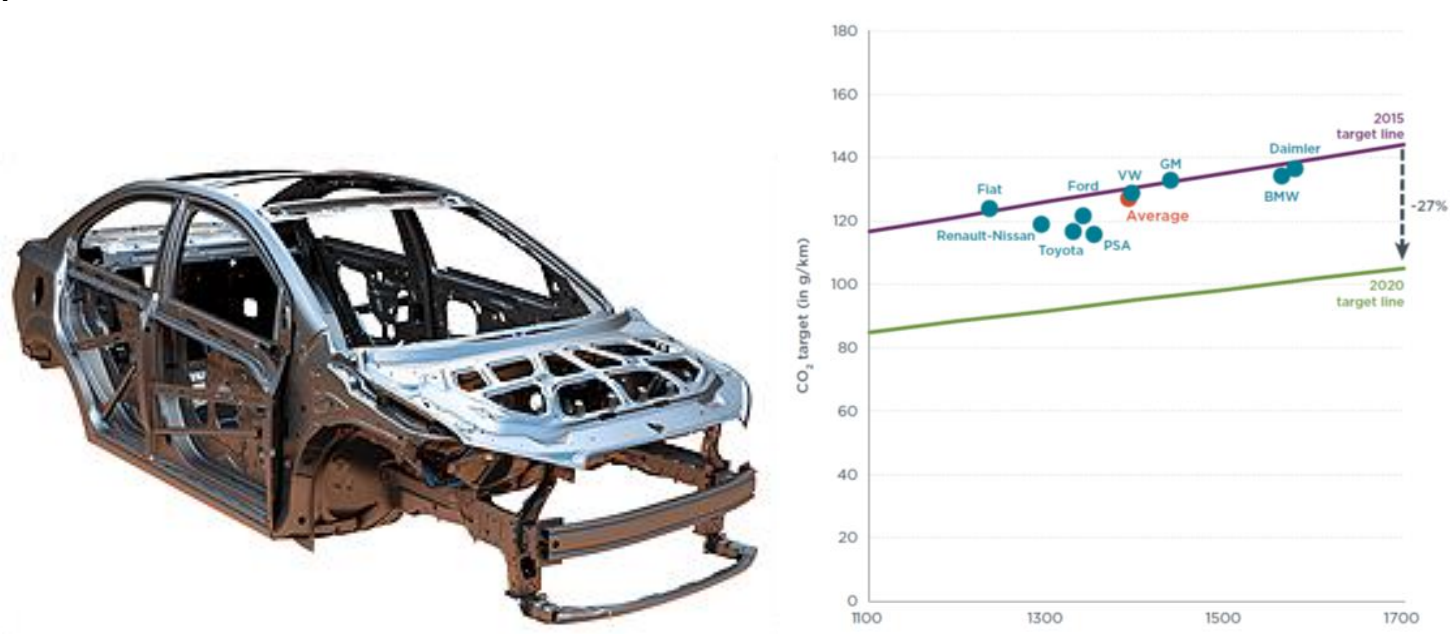

Figure 3: Decreasing the weight of the "Body in White" (BIW) Figure 4: BIW for European car manufacturers

(Source: ICCT Report June 2014: $\mathrm{CO}_{2}$ emissions from new passenger cars in the EU: Car manufacturer performance in 2013)

The key variables to reduce GHG by improving vehicle efficiency include improved engine efficiency (42\%), reduced vehicle weight (24\%), improved aerodynamics $(19 \%)$, and reduced rolling resistance (15\%). Shrinking vehicle size provides an additional option to trim fuel consumption. Standards and incentives both increase fuel economy and reduce fuel consumption, terms that are often used in this report.

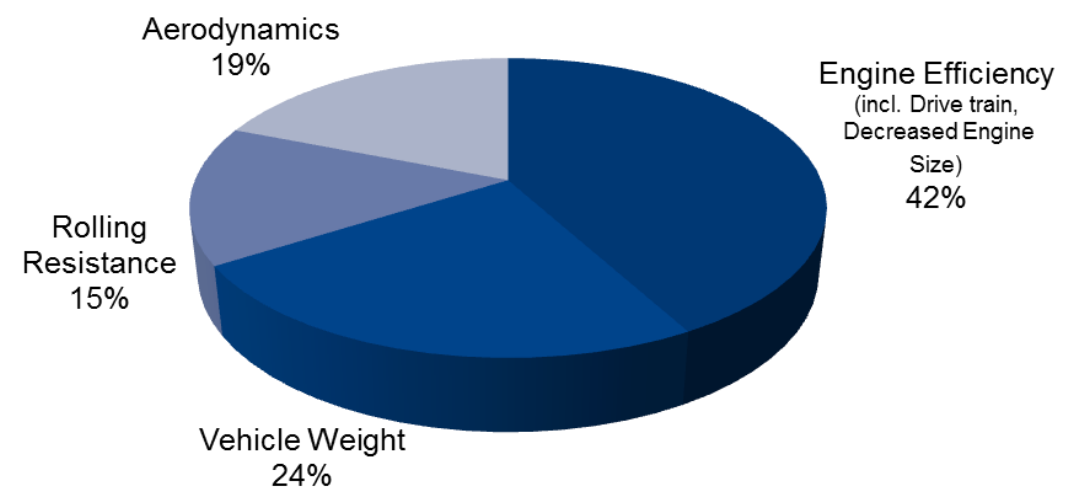

Figure 4.

Intelligent material selection has great opportunities in weight reduction. By choosing the right material weight reduction of more than $30 \%$ is possible. Figure 5 shows an example of the possible weight reduction achieved by the use of AHSS.

* Technical contribution to the 51st Rolling Seminar - Processes, Rolled and Coated Products, October $28^{\text {th }}$ to $31^{\text {st }}, 2014$, Foz do Iguaçu, PR, Brazil. 


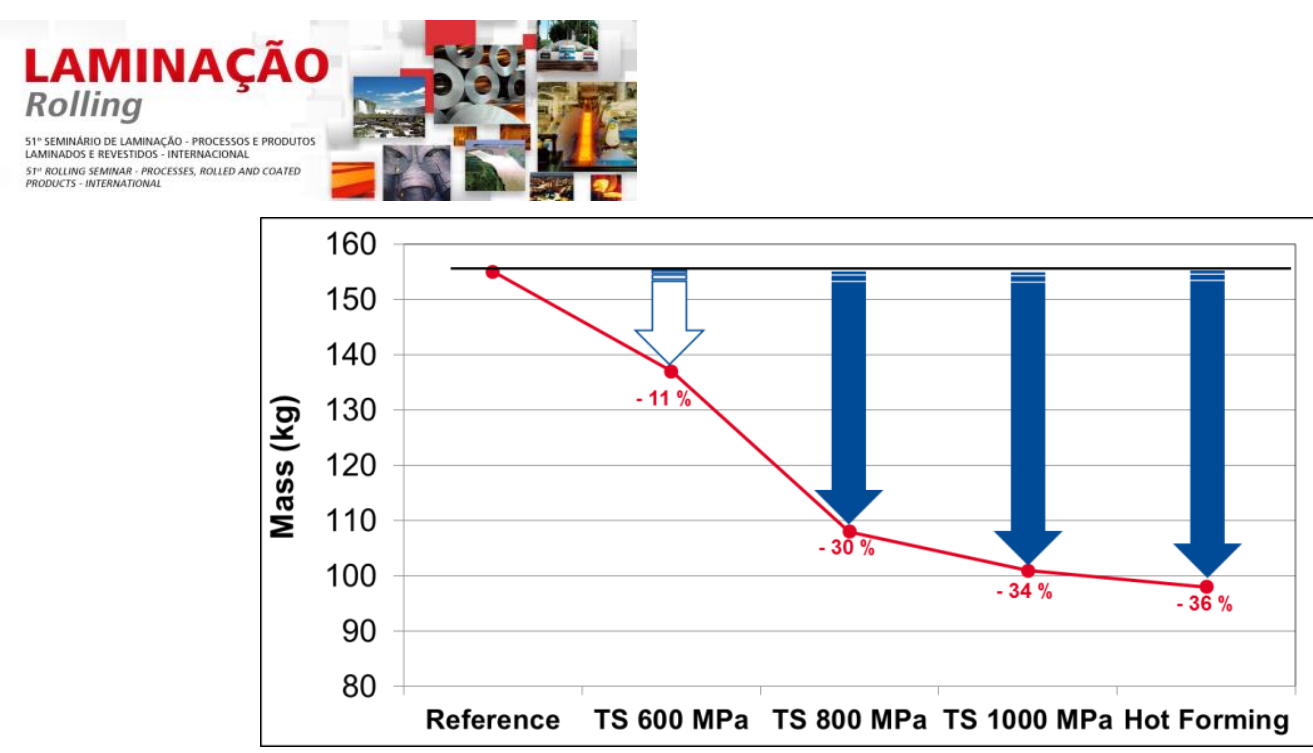

Figure 5: Possible weight reduction by material substitution

The focus is on weight reduction by using AHSS and UHSS for the automotive industry. Conventional high strength steels were manufactured by adding the alloying elements in small amounts and could be manufactured under relatively simple processing conditions and have widely been applied for weight reduction. The strength of novel advanced high strength steels is controlled by addition of alloying elements such as $\mathrm{Mn}, \mathrm{Si}, \mathrm{Cr}, \mathrm{Nb}, \mathrm{Ti}, \mathrm{P}$ or $\mathrm{Al}$, which dissolve in the base matrix and create a solute or precipitation strengthening effect. Due to the high amount of readily oxidized alloys, AHSS and UHHS tend to the well-known galvanizing problems:

- Wettability and adhesion problems during the hot dipping of steel grades which are alloyed with high amounts of $\mathrm{Mn}, \mathrm{Si}, \mathrm{Cr}$ or Al. These elements tend to form oxides on the steel surfaces during recrystallization annealing due to the presence of residual $\mathrm{O}_{2}$ and $\mathrm{H}_{2} \mathrm{O}$ in the annealing atmosphere [5-8].

- Reheating problems of UHSS (DP1200) during galvannealing process. $\mathrm{MET} / \mathrm{Con}$ has the Know-How for necessary sophisticated industrial production processes and strategies such as:

a) Pre-oxidation techniques,

b) Cooling technology and strategies,

c) Galvannealing phenomenon of DP1200.

\section{PRE-OXIDATION TECHNIQUES FOR HIGH ALLOYED STEEL GRADES}

Wettability and adhesion problems during the hot dipping of high alloyed steel grades can be solved in different ways. One way is the chemical solution where oxide loving alloying elements like Si or Mn are substituted by adding less effective components such as Al or Mo which lead to lower wetting problems. The disadvantages of this practice are higher alloying costs and a more difficult steel making process. Another way to improve the galvanizing behavior of AHSS and UHSS is based on an industrial process solution, where these alloys are pre-oxidized within the substrate. The oxidation of the alloying elements are influenced in a way that external oxidation on the strip surface changes into internal oxidation according to the model of Wagner [9].

Such a process solution has been jointly developed by MET/Con together with Drever International - the technology leader with regard to furnace equipment, process control and equipment performance - together with our partner we provide two solutions in regard to pre-oxidation:

Due to the fact that only iron can be reduced under industrial annealing conditions $\left(5 \% \mathrm{H}_{2} / 95 \% \mathrm{~N}_{2}\right)$, it is the goal of pre-oxidation processes to create a very thin

\footnotetext{
* Technical contribution to the 51st Rolling Seminar - Processes, Rolled and Coated Products, October $28^{\text {th }}$ to $31^{\text {st }}, 2014$, Foz do Iguaçu, PR, Brazil.
} 


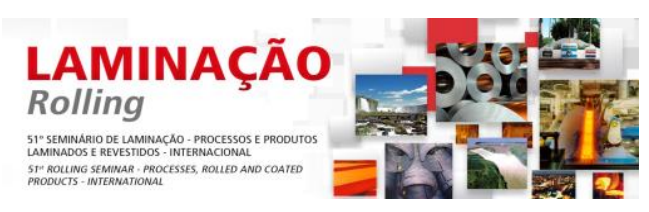

"external" Fe-oxide layer of maximum 150 to $200 \mathrm{~nm}$ on the strip surface [10]. This thickness can be reduced later on in the annealing furnace with the available time and temperatures. This practice is well known for improving the surface quality of hot-dipped galvanized (GI) or galvannealed (GA) coated AHSS / UHSS.

Two procedures are introduced in this paper:

- Pre-oxidation in the direct fired preheating furnace (DFF) and

- Pre-oxidation in a separate reactive zone in the radiant tube furnace (RTF).

Even though the interaction of oxygen reactive alloying elements with the annealing / combustion gases is the subject of many investigations, the pre-oxidation for promoting internal oxidation is a very sensitive procedure. The process parameters are accompanied with high maintenance efforts to stabilize a small production window where the thin Fe-oxide layer of up to $2 \mathrm{~g} / \mathrm{m}^{2}$ can be formed at the strip surface and alloying elements are enriched internally.

\subsection{Pre-Oxidation (DFF)}

The atmospheric conditions in the preheating zone can be changed from oxidizing to reducing by adjusting the air-fuel-ratio of the burner gas. The thickness and the distribution of the Fe-oxide layer is highly dependent on the Lamda $(\lambda)$-value, which narrows the production window. Therefore, the last zone of the DFF is operating under oxidizing combustion (Lambda-ratio = air/gas-ratio > 1). Small differences in the air/gas-ratio can create soot and/or undefined oxide-layer thicknesses. Also the transient control is difficult to manage or needs additional production resources (capacity/material). Another influencing factor is the strip dimension. Due to the available reactive strip surface and also the distance of strip edges to the burners, wide strips react differently to different $\lambda$-values than narrow strips. The exposure time of the strip surface to the oxidizing atmosphere is very short to create a Fe-oxide layer of the required thickness. Furthermore, the external Fe-oxidization on the strip surfaces modifies the emissivity and the heat transfer which makes the strip temperature control even more difficult. The strip temperature can vary by $50{ }^{\circ} \mathrm{C}$. The reduction of the Fe-oxide-layer is executed in the radiant tube furnace which requires a higher amount of Hydrogen compared to regular industrial standards. The reduction of $\mathrm{Fe}$-oxides creates $\mathrm{H}_{2} \mathrm{O}$ in the furnace atmosphere. The $\mathrm{H}_{2} \mathrm{O}$ dissociates into $\mathrm{H}_{2}$ and $\mathrm{O}_{2}$. Subsequently, the $\mathrm{O}_{2}$ reacts with the carbon of the steel and leads to decarburization and soot pollution in the furnace enclosure during reduction of FeO. Beside a better atmosphere management, a higher $\mathrm{H}_{2}$-content can increase the danger of brittleness and coating bubbles. Due to the fact that $\mathrm{H}_{2}$ and $\mathrm{H}_{2} \mathrm{O}$ are in interaction, both values will be changed by adapting the $\mathrm{H}_{2}$-content. At conditions with higher dew points (DP), decarburization is significantly encouraged.

\subsection{Pre-oxidation in RTF}

Most of the new galvanizing lines which produce automotive steels are equipped with radiant tube furnaces (RTF). The RTF limits the possibility of changing atmospheric conditions like the $\lambda$-value without DFF. Reduction of the alloying elements with very high affinity for oxygen is not possible under the prevailing conditions. Varying the partial pressure of oxygen in the annealing gas atmosphere offers an alternative approach by means of which the location of the oxidation of the alloying components can be changed. Some companies started investigations with slotted radiant tubes to influence the furnace atmosphere. In general, this procedure works but it is not

\footnotetext{
* Technical contribution to the 51st Rolling Seminar - Processes, Rolled and Coated Products, October $28^{\text {th }}$ to $31^{\text {st }}, 2014$, Foz do Iguaçu, PR, Brazil.
} 


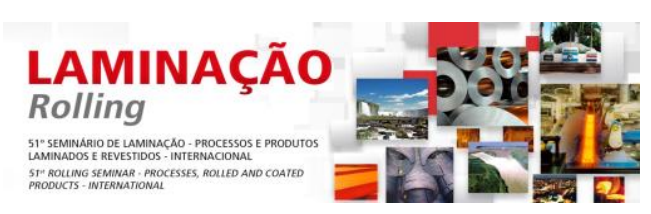

controllable due to different reasons. One critical point is that the holes in the tubes are always open and cannot be closed even if they are not needed.

Generally, the industrial use of the oxidation/reduction techniques in a RTF requires an oxygen feed-in point in order to control the moisture of the controlled annealing atmosphere. Beside that the industry had to face several problems such as reactive zone size and place, safety concepts, and atmosphere transfer to the strip, etc. Drever International has engineered different solutions for the galvanizing industry in order to handle all of these challenges. A pre-oxidation chamber (reactive zone) was developed and successfully integrated between the heating zone and the soaking zone in order to carry out the oxidizing of the strip surface independently of the remaining furnace atmosphere. The pre-oxidation is executed with minimal quantities of oxygen - approx. $0.2 \%$ - at temperatures between $750^{\circ} \mathrm{C}$ and $850^{\circ} \mathrm{C}$. With a separate reactive zone in the annealing furnace it is possible to adjust the oxidation condition very precisely. By this, the Fe-oxide-layer thickness is controllable at any time during production. The length of this chamber is between 10 to $14 \mathrm{~m}$, which limits the exposure time to a few seconds. The injection of the atmosphere is close to the strip surface and can be controlled by way of $\mathrm{O}_{2}$-concentration, amount of contaminated gas, and pressure. The atmosphere of this reactive zone is easy to control.

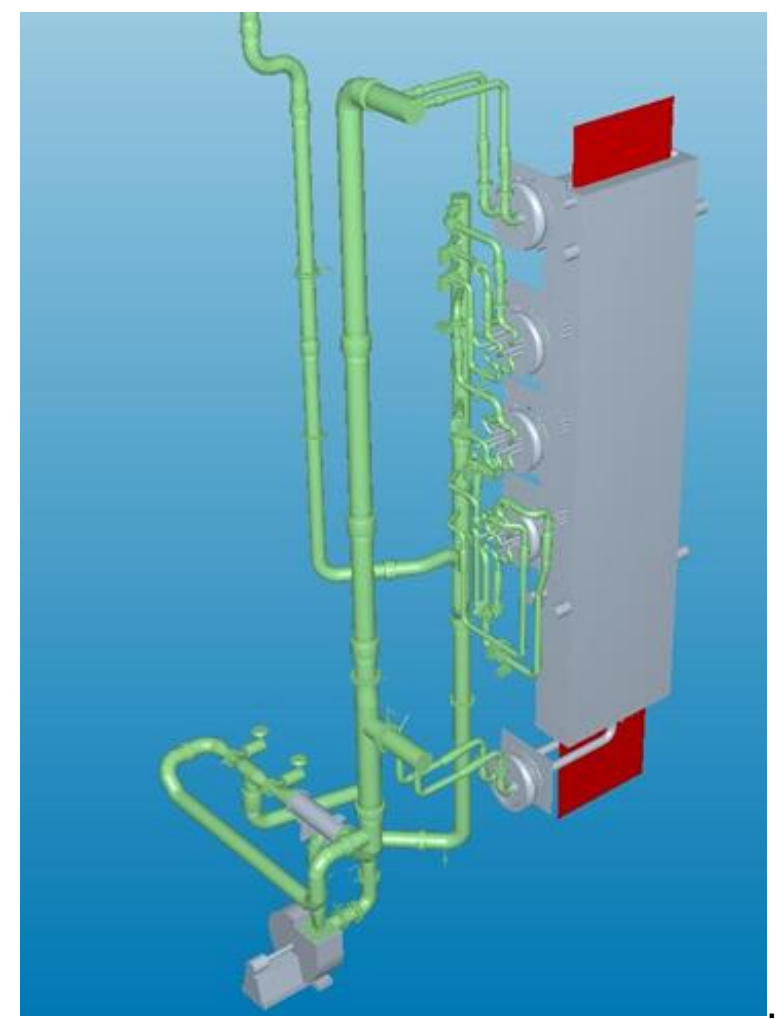

Figure 6: Oxidation chamber designed by DREVER INTERNATIONAL

An alternative to the described selective oxidation process is the usage of a precoating in front of the annealing furnace. An electrochemically pre-deposited metallic coating (e.g. Fe-Ni) of 2-3 $\mu$ m-thickness covers the strip surface during the intercritical annealing step. The metallic coating hinders the diffusion of the alloying elements to the strip surface which improves the wettability of AHSS and UHSS. This method is very costly and is not a subject of this consideration.

\footnotetext{
* Technical contribution to the 51st Rolling Seminar - Processes, Rolled and Coated Products, October $28^{\text {th }}$ to $31^{\text {st }}, 2014$, Foz do Iguaçu, PR, Brazil.
} 


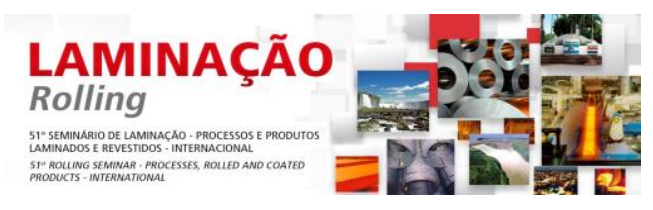

Another solution to coat AHSS is the stabilizing of the dew point by adding water into the annealing furnace. Moisture forms due to the addition of oxygen, the formation of iron oxide and the subsequent reduction step. This water raises the oxidation potential of the gas atmosphere, thus ensuring a stable production of AHSS. This solution is also not a subject of this paper. The gas is initially directed through the water vaporizer. The process gas which flows over the surface of the fluid is somewhat saturated and leaves the room in the direction of the condenser which has a lower temperature. This results in a water vapor which is supersaturated - and the gas subsequently flows to the mixing unit with an absolutely defined and therefore precise dew point. [11]
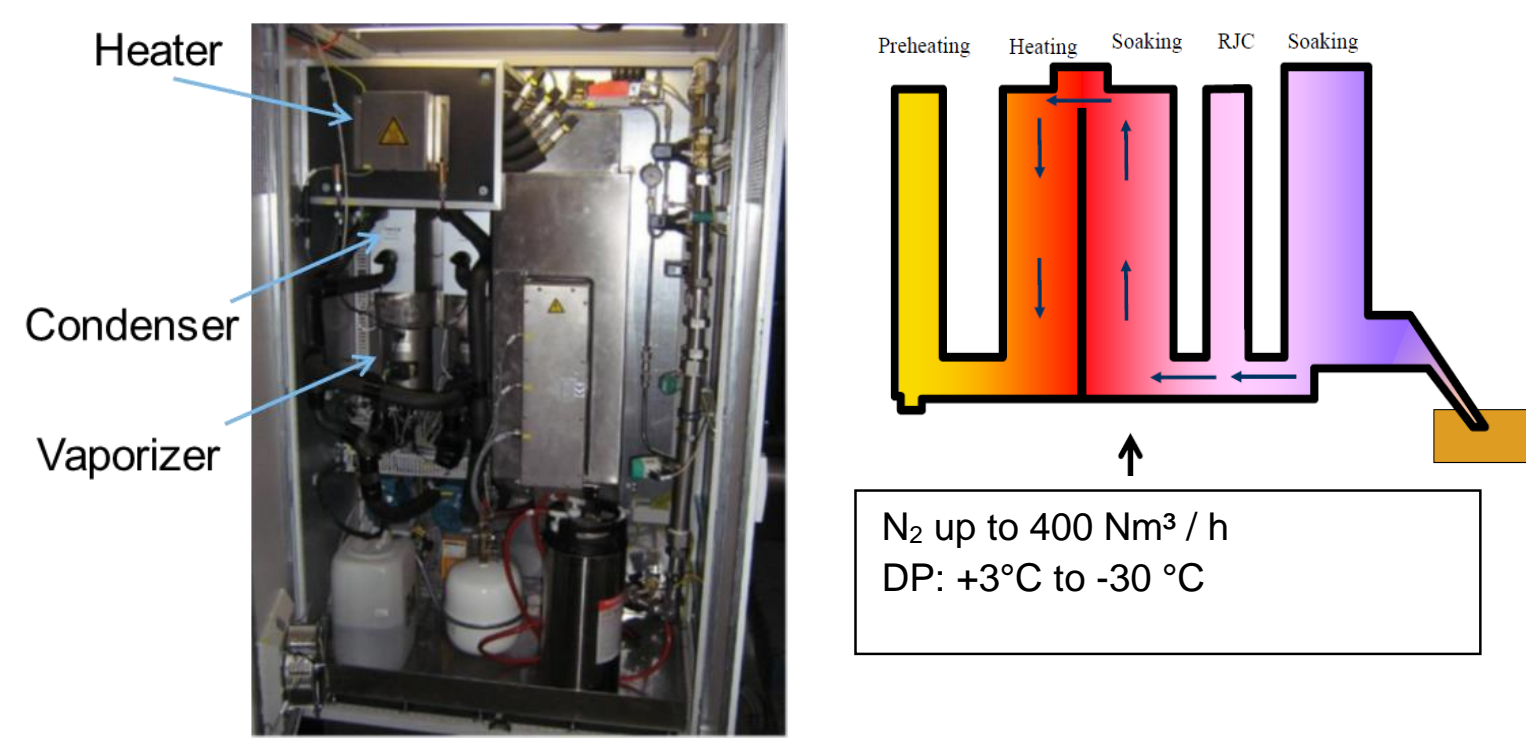

$\mathrm{N}_{2}$ up to $400 \mathrm{Nm}^{3} / \mathrm{h}$

DP: $+3^{\circ} \mathrm{C}$ to $-30^{\circ} \mathrm{C}$

Figure 7: Example for a dew point stabilization system

\section{COOLING TECHNOLOGY FOR CAL AND CGL}

After heating up and equalizing the strip temperature, the strip has to be cooled in a certain, pre-defined way to achieve the desired mechanical properties. Depending on different steel grades and final mechanical properties, it can be necessary to cool the strip with a smooth cooling rate (diffusion controlled transformation) or in the fastest possible way with gas cooling or water quenching devices (bainite and/or martensite transformation).

Depending on the cooling equipment in the furnace, cooling rates from 15 up to 500 $\mathrm{K} / \mathrm{s} / \mathrm{mm}$ can be realized. High cooling rates are needed for high strength steel grades and for soft low carbon steels with subsequent overageing. Figure 8 summarizes and describes different cooling technologies.

\footnotetext{
* Technical contribution to the 51st Rolling Seminar - Processes, Rolled and Coated Products, October $28^{\text {th }}$ to $31^{\text {st }}, 2014$, Foz do Iguaçu, PR, Brazil.
} 


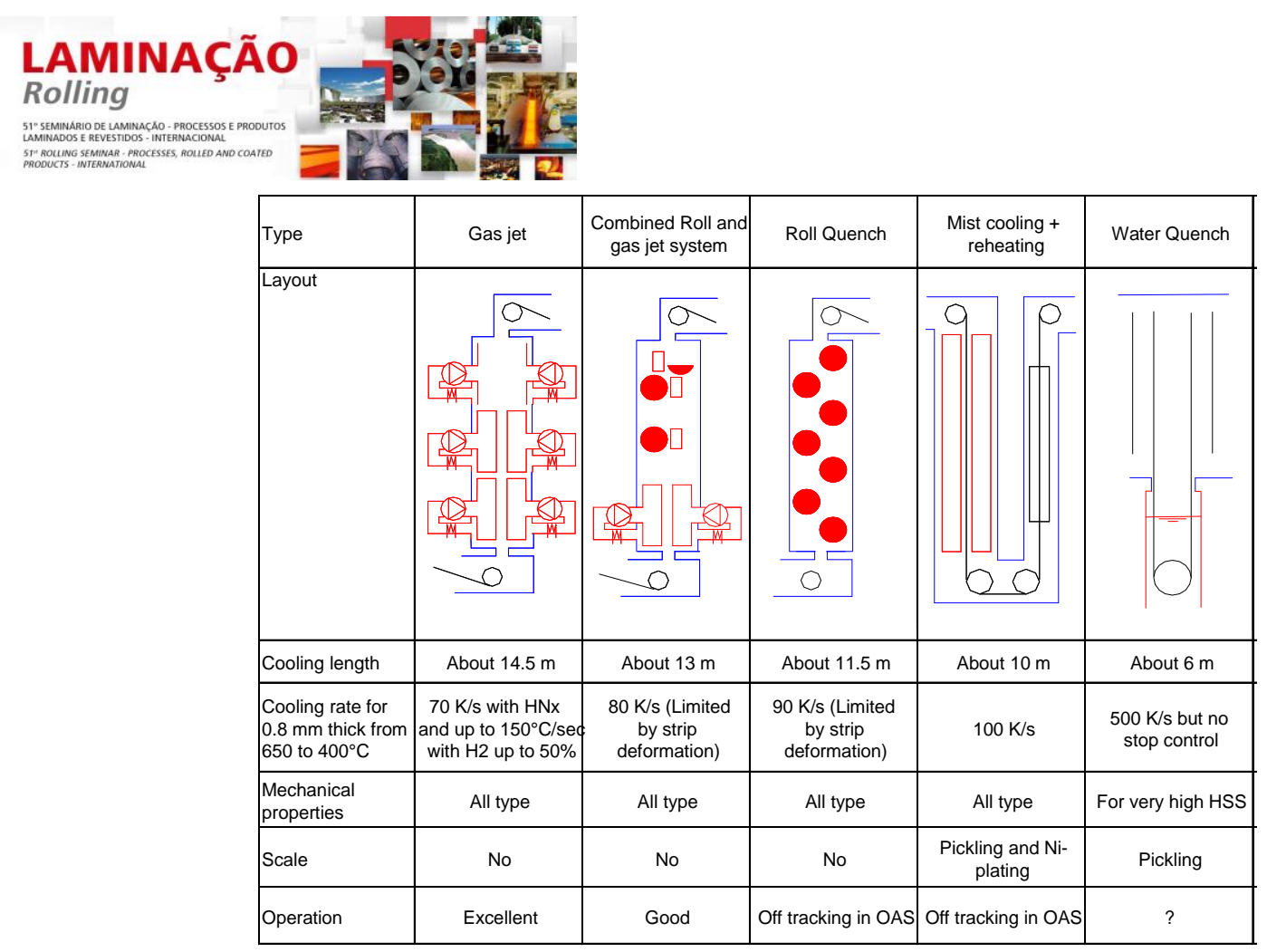

Figure 8: Cooling technologies for AHSS and UHSS (Source: DREVER INTERNATIONAL)

For some steel grades it is necessary to cool the strip slowly so that austenite can transform into ferrite. The carbon in excess can diffuse from the ferrite into the austenite or can form carbides which are already present. The carbides become coarser and less harmful then pearlite. The slow cooling section operates with cooling rates up to $20 \mathrm{~K} / \mathrm{s}$ which is mainly used for IF steels. This smooth rate is the cheapest and easiest possibility for cooling and is sufficient for some commercial steel grades. The slow cooling rate for Al-killed steel must be $\leq 10^{\circ} \mathrm{C} / \mathrm{s}$. There is no defined lower limit, but if the cooling rate is too low, the required furnace length increases which will increase the cost for the furnace. In Ultra Low Carbon (ULC) grades, the carbon content is too low to form carbides. Slow cooling is useless for these grades.

The strip travel in the cooling section is done in the same way as described above. The atmosphere in this section consists of protective gas as explained above additionally with a small percentage of hydrogen (2 to $5 \%$ ).

The strip temperature at the end of the slow cooling section is more or less $650^{\circ} \mathrm{C}$ (which is just below $A_{c 1}$ of the iron-carbon-diagram).

\subsection{Rapid Gas Cooling Zone}

To obtain the necessary microstructure of the steel strip with the requested mechanical properties, the cooling has to be done as effectively as possible regarding temperature range and cooling rate. Therefore, the cooling time should be as short as possible. To reach this target, the strip is charged with cold protective gas which can have a high percentage of hydrogen of 20 to $30 \%$ to achieve highest possible cooling rates. This protective gas is cooled down in heat exchangers working on gas/water basis. A series of jet blowers are located one above the other to arrange the cooling. The aspiration temperature of the cooled protective gas is around $60^{\circ} \mathrm{C}$ at the outlet of the blower tubes which are on both sides of the strip. The blowing is done by highly efficient blowers. To avoid that air from the outside comes into the process, the blowers are sealed by injection of nitrogen. The minimum finish temperature of the cooling step is approximately $270^{\circ} \mathrm{C}$ PMT (peak

\footnotetext{
* Technical contribution to the 51st Rolling Seminar - Processes, Rolled and Coated Products, October $28^{\text {th }}$ to $31^{\text {st }}, 2014$, Foz do Iguaçu, PR, Brazil.
} 


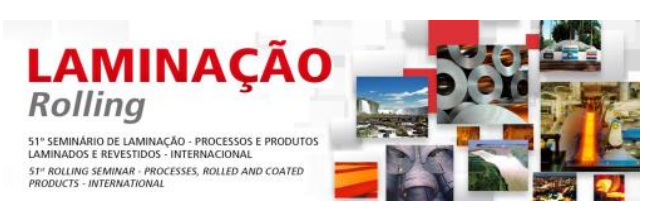

metal temperature). Depending on the cooling equipment in the furnace, cooling rates from $15 \mathrm{~K} / \mathrm{s} / \mathrm{mm}$ up to $100 \mathrm{~K} / \mathrm{s} / \mathrm{mm}$ can be realized. High cooling rates are needed for high strength steel grades which go along with higher hydrogen contents. If a blower or heat exchanger fails, it can be shut-off without stopping the line. Normally, the control of the section is done by PMT measurement of the strip. Small leakages are normally repaired during scheduled maintenance stops.

A sealing chamber is installed between cooling section and overaging zone to avoid heat transfer from the cooling section into the overaging zone.

\subsection{Roll Quench}

Roll quenching technologies enable a higher cooling rate than rapid gas cooling. In this solution, the strip is cooled down by water cooled deflector rolls. The main advantage of the process is that the treatment takes place in protecting gas atmosphere so that no oxidation occurs. The strip tension in the beginning can be increased a little but is in the range of 5 to $10 \mathrm{MPa}$ because of the high strip starting temperatures and resulting rather soft material. Later-on the strip tension can be increased due to the quickly dropping strip temperatures. The increased tension depends on the strip dimensions. Thinner material is processed with higher specific tensions, whereas thicker material is processed with lower specific tensions.

The roll quench cooling is very effective but the process is completely unstable, so that this solution is not used any more since the main problem of roll quenching was not solvable: If strip buckling starts and parts of the surface are not in contact with the rolls, these parts are no longer cooled down so that buckling becomes even worse. As a result, the strips often broke.

\subsection{Water Quench}

Cooling rates higher than $500 \mathrm{~K} / \mathrm{s}$ are possible with water quench cooling. Different systems are possible. The most common systems are water quenching devices with cold water. The advantage of water cooling is the possibility to reach high cooling rates in order to produce very high strength steel grades. The disadvantages are higher investment and operating costs. Due to the formation of a thin oxide layer caused by the impact of the cooling water, an additional pickling and cleaning of the strip is necessary to achieve an adequate surface quality for further processing. Nevertheless, the water cooling technology of the SMS group members cover all current requests to enable the best possible performance.

\section{GALVANNEALING AND COOLING TECHNIQUES FOR DP1200}

During production of UHSS with $1200 \mathrm{MPa}$ tensile strength a new phenomenon occurs at the inductive heating system of the galvannealing section. Even by applying full power the material cannot be heated up fast enough for the galvannealing process. This effect slows down the production of such a material and deteriorates the surface quality.

The difficulty to galvanneal these steel grades can be described as follows:

The magnetic permeability (relative permeability $\mu \mathrm{r}$ ) is the important value to be regarded in this context. A non-ferromagnetic material has $\mu r=1$, whereas a ferromagnetic material has $\mu r \geq$ (above) 1 . It is important to know the dependence of $\mu \mathrm{r}$ from the temperature and from the alloying degree and kind. For example, pure Fe

\footnotetext{
* Technical contribution to the 51st Rolling Seminar - Processes, Rolled and Coated Products, October $28^{\text {th }}$ to $31^{\text {st }}, 2014$, Foz do Iguaçu, PR, Brazil.
} 


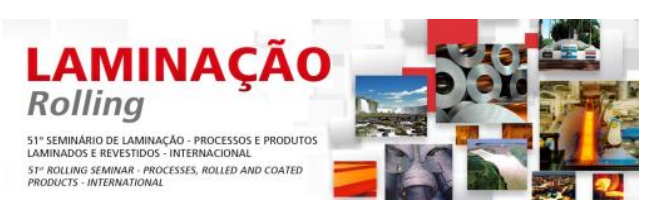

has a Curie-Point of $768^{\circ} \mathrm{C}$. If it is alloyed with $3 \% \mathrm{Si}$, the Curie-Point changes to $746^{\circ} \mathrm{C}$. In practical application we find an "effective Curie-Point" less than $746^{\circ} \mathrm{C}$. The reason is that the permeability does not jump from high values to 1 . The "effective Curie-Point" of a Fe - $3 \% \mathrm{Si}$-alloying is at $\approx 720^{\circ} \mathrm{C}$. This means the ferromagnetic material can be heated up very fast until the effective Currie-point and above only with a much lower heating rate.

After intercritical annealing of $1200 \mathrm{MPa}$ UHSS-grade above $800{ }^{\circ} \mathrm{C}$ and prior to galvanizing, the material will be cooled down with more than $50 \mathrm{~K} / \mathrm{s}$. By this, austenite is transformed into martensite with typical volume fractions of martensite up to $70 \%$.

The precondition for inductive heating is a permeability of the material of $>1$. At this stage the heating system (inductor) cannot transfer sufficient energy into the strip due to the high amount of martensite which shows a disadvantageous magnetic permeability which is close to the austenite permeability of $\mu r=1$, which means nonmagnetic.

A solution for this phenomenon is currently a matter of research and development.

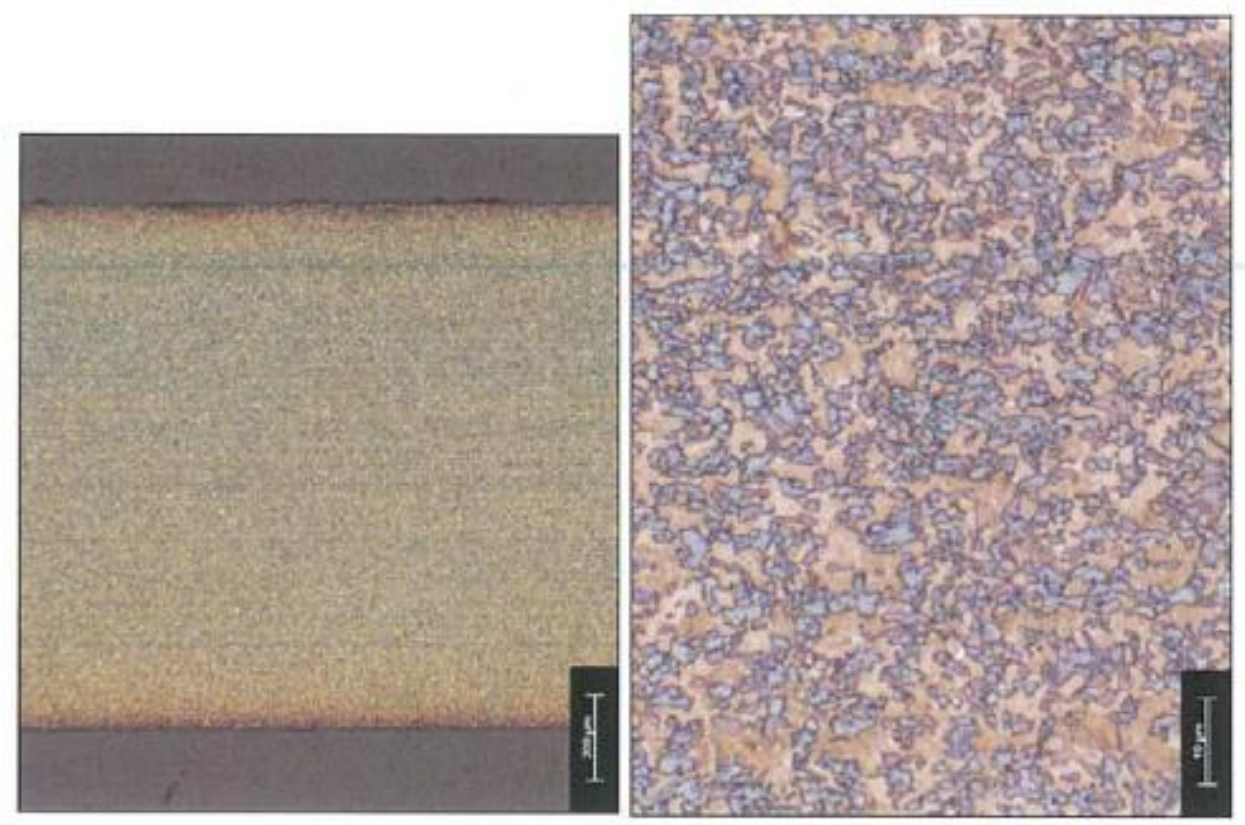

Figure 9: Microstructure of a DP1200 (blue = ferrite; brown = martensite)

\section{CONCLUSIONS}

Innovative, weight-reducing steel concepts offer great potential in lightweight automotive construction and lead to a sustainable reduction in $\mathrm{CO}_{2}$ emissions. Preoxidation technology is an innovative process for guaranteeing the suitability of AHSS and UHSS for hot-dip galvanizing and significantly improves surface quality.

The implementation of the technology in existing lines is possible. Furthermore, this innovative technology represents a fundamental component in the planning of new hot-dip galvanizing lines and expands the production capacity of existing facilities. By ensuring zinc wetting and adhesion, oxidation/reduction technology is making a decisive contribution to developing the market potential of multiphase steels in automotive manufacturing.

- Novel AHSS / UHSS alloying concepts require highly sophisticated production processes which can be offered by MET/Con and DREVER INTERNATIONAL

\footnotetext{
* Technical contribution to the 51st Rolling Seminar - Processes, Rolled and Coated Products, October $28^{\text {th }}$ to $31^{\text {st }}, 2014$, Foz do Iguaçu, PR, Brazil.
} 


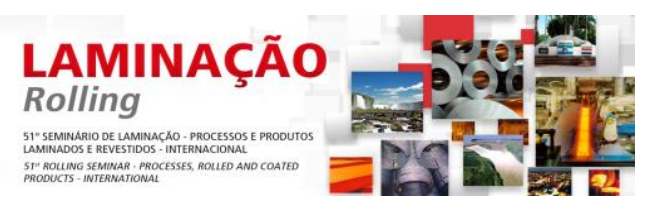

- These steel grades allow a significant decrease of the vehicle weight with the same (or improved) crash performance, with an important impact on $\mathrm{CO}_{2}$ emission per $\mathrm{km} /$ mileage per gallon

- To be in competition with lightweight material is the force to develop AHSS / UHSS grades; these grades offer great opportunity for car manufactures to meet the requirements of CAFE-standards and NHTSA

- Understanding how surface chemistry and subsurface structure are controlled by annealing conditions is the key to developing next-generation technologies. Next-generation Know-How and equipment can be offered by MET/Con and DREVER.

\section{REFERENCES}

1 Block H, Marten T, Tröster T. Crash Simulation of high strength automotive components using advanced failure models; SCT (2014) 126-133

2 ICCT, Global Transportation Energy and Climate Roadmap; 2012

3 2017-2025 Corporate Average Fuel Economy Compliance and Effects Modeling System Documentation National Highway Traffic Safety Administration

4 http://www.nhtsa.gov/Laws+\&+Regulations/Vehicles?rulePage $=0$

5 Swaminathan S, Spiegel M. Appl. Surf. Sci. 253 (2007) 4607-4619.

6 Ollivier-Leduc A, M.-L. Giorgi, D. Balloy, J.-B. Guillot, Corros. Sci. 52 (2010) 2498-2504

7 Li XS, Baek S-I, Oh C-S, Kim S-J, Kim Y-W. Scipta Mater. 57 (2007) 113-116

8 A. Ollivier-Leduc, Giorgi M-L, Balloy D, J.-B. Guillot J-B. Corros. Sci. 53 (2011) 13751382

9 Wagner C. Reaktionstypen bei der Oxydation von Legierungen, Z. Elektrochem. 63 (1959) 772

10 Norden M, Blumenau M, Schönenberg R. Recent trends in hot-dip galvanizing of ahvanced high.strength steel at ThyssenKrupp Steel Europe, AISTech (2012)

11 DewCal, Falk Steuerungssysteme GmbH; http://www.falkgmbh.com/EN/dewcal-01.html

* Technical contribution to the 51st Rolling Seminar - Processes, Rolled and Coated Products, October $28^{\text {th }}$ to $31^{\text {st }}$, 2014, Foz do Iguaçu, PR, Brazil. 